\title{
Impact of a physician recommendation and parental immunization attitudes on receipt or intention to receive adolescent vaccines
}

Lisa M Gargano ${ }^{1, *}$, Natasha L Herbert ${ }^{1}$, Julia E Painter1, Jessica M Sales', Christopher Morfaw², Kimberly Rask', Dennis Murray³, Ralph J DiClemente', and James M Hughes'

'Emory University; Atlanta, GA USA; ${ }^{2}$ East Central Health District; Georgia Department of Public Health; Augusta, GA USA; ${ }^{3}$ Georgia Regents University; Augusta, GA USA

Keywords: adolescent, vaccine, attitudes, health belief model, theory of reasoned action

Four vaccines are recommended by the Centers for Disease Control and Prevention's Advisory Committee on Immunization Practices for adolescents. Parental attitudes may play a key role in vaccination uptake in this age group. In 2011, we conducted a cross-sectional survey among parents of adolescents in one county in Georgia to identify parental attitudes toward adolescent vaccination, reasons for vaccine acceptance or refusal, and impact of a physician recommendation for vaccination. Physician recommendation was reported as one of the top reasons for receipt or intent to receive any of the vaccines. Physician recommendation of any of the four vaccines was associated with receipt of Tdap ( $p<0.001)$, MCV4 $(p<0.001)$, and HPV $(p=0.03)$ and intent to receive Tdap $(p=0.05)$, MCV4 $(p=0.005)$, and HPV $(p=0.05)$. Compared with parents who did not intend to have their adolescent vaccinated with any of the vaccines, parents who did intend reported higher perceived susceptibility (3.12 vs. $2.63, p=0.03$ ) and severity of disease (3.89 vs. $3.70, p=0.02$ ) and higher perceived benefit of vaccination ( $8.48 \mathrm{vs} .7 .74, p=0.02$ ). These findings suggest that future vaccination efforts geared toward parents may benefit from addressing the advantages of vaccination and enhancing social norms. Physicians can play a key role by providing information on the benefits of adolescent vaccination.

\section{Introduction}

The Centers for Disease Control and Prevention's Advisory Committee on Immunization Practices (ACIP) recently expanded its recommended immunization schedule for adolescents to include three vaccines specifically targeted toward adolescents: tetanus, diphtheria, and acellular pertussis (Tdap), quadrivalent meningococcal-conjugate (MCV4), and human papillomavirus $(\mathrm{HPV})$ vaccines, as well as annual vaccination against influenza. ${ }^{1}$ Given the increasing number of recommended vaccines for adolescents, low vaccination rates currently among adolescents for these four recommended vaccines, and the morbidity, mortality, and economic costs associated with non-vaccination for vaccine preventable diseases, it is a public health imperative that effective strategies for increasing vaccination rates among adolescents are developed and implemented. Increasing adolescent vaccination rates is especially important in certain states, such as Georgia, where adolescent vaccination rates are lower than the national average. $^{2}$

Several studies have identified potential barriers to increasing adolescent immunization rates, including: vaccine cost: ${ }^{3,4}$ providerrelated barriers such as storage and monitoring, vaccine knowledge and attitudes toward vaccination, and missed opportunities; 5 vaccination venue and the need for informed consent; ${ }^{6}$ adolescent health care utilization patterns; ${ }^{7}$ and vaccine acceptance among parents and adolescents. ${ }^{5,8,9}$ Strategies have been suggested to reduce many of these barriers, including subsidizing or reducing vaccine costs, enhancing physicians' knowledge and attitudes regarding adolescent vaccination, and reducing missed opportunities. ${ }^{5}$ Frequently discussed strategies also include addressing adolescent and parental concerns regarding vaccination ${ }^{5,6,10}$ and providing vaccinations in settings outside medical homes, including schools. ${ }^{11,12}$

Research suggests that parental attitudes are important determinants of vaccine uptake. With respect to HPV vaccination, studies have shown that, among parents, low knowledge of HPV, low perceived susceptibility of adolescents to HPV/sexually transmitted infections, concerns about vaccine safety, and views that HPV vaccination leads to sexual activity have been associated with reluctance to allow HPV vaccination. ${ }^{13}$ For influenza vaccination, studies have found that, among parents, perceived barriers to vaccination, ${ }^{14,15}$ fear of adverse events, ${ }^{16}$ and not believing in any vaccinations have been associated with influenza vaccine refusa ${ }^{16}$ while perceiving that influenza vaccination is the social norm ${ }^{15}$ has been associated with influenza vaccine acceptance. For meningococcal vaccination, research among parents has shown 
Table 1. Adolescent demographics and characteristics

\begin{tabular}{|c|c|}
\hline & $\begin{array}{c}\text { Responses } \\
(\mathrm{n}=114) \\
\mathrm{N}(\%)\end{array}$ \\
\hline \multicolumn{2}{|l|}{ Race } \\
\hline White & $16(13.7)$ \\
\hline African American & $89(76.1)$ \\
\hline Other & $12(10.3)$ \\
\hline \multicolumn{2}{|l|}{ Gender } \\
\hline Male & $52(44.4)$ \\
\hline Female & $65(55.6)$ \\
\hline \multicolumn{2}{|l|}{ Age } \\
\hline Years (mean [SD]) & $13.8(1.9)$ \\
\hline \multicolumn{2}{|l|}{ Health insurance } \\
\hline Medicaid & $70(59.8)$ \\
\hline Private insurance & $43(36.8)$ \\
\hline Other & $4(3.4)$ \\
\hline \multicolumn{2}{|l|}{ Prior receipt of vaccine } \\
\hline Influenza & $76(82.6)$ \\
\hline Tdap & $98(83.8)$ \\
\hline MCV4 & $80(68.4)$ \\
\hline HPV (at least one dose) & $48(41.0)$ \\
\hline HPV (three doses) (of those who received one dose) & $32(66.7)$ \\
\hline \multicolumn{2}{|l|}{ If not received vaccine, intend to receive } \\
\hline Influenza & $44(58.9)$ \\
\hline Tdap & $14(87.5)$ \\
\hline MCV4 & $25(73.5)$ \\
\hline HPV & $47(71.1)$ \\
\hline \multicolumn{2}{|l|}{ Physician recommendation for vaccine } \\
\hline Influenza & $66(72.5)$ \\
\hline Tdap & $78(66.7)$ \\
\hline MCV4 & 85 (72.7) \\
\hline HPV & $60(51.3)$ \\
\hline
\end{tabular}

that higher perceived vulnerability of their child to contracting the disease was related to a more positive attitude toward vaccination, while higher perceived control in being able to prevent an infection was related to a higher level of concern about the safety, usefulness, and effectiveness of vaccination. ${ }^{17}$ There are very limited data available for the role of parental attitudes in influencing Tdap vaccine acceptance. One study found that lack of knowledge about the vaccine led to Tdap vaccine refusal. ${ }^{18}$

This study served as a baseline survey of parents of adolescents residing in a large county in Georgia to examine: (1) parental immunization attitudes, (2) reasons for receipt or intention to have their adolescent receive recommended vaccines, (3) importance of physician recommendation for vaccination, and (4) psychosocial factors associated with receipt or intention to have their adolescent receive a recommended vaccine.

\section{Results}

Demographics and vaccination history

The majority of adolescents inquired about in the survey were African American (76.1\%), and just over half were female (55.6\%) (Table 1). The mean age was 13.8 y (SD +/- 1.9). Over half of parents $(59.8 \%)$ reported that their adolescent(s) was/ were covered by Medicaid (Table 2).

Overall there was relatively high baseline coverage for all four vaccines recommended for adolescents. HPV vaccine coverage was the lowest, at $41.0 \%$; Tdap vaccine coverage was the highest, at $83.8 \%$ (Table 2 ). There was a relatively high proportion of intent to receive vaccination among those who were not up-todate on the vaccines. Over $70 \%$ intended to have their adolescent receive the HPV and MCV4 vaccine and $87.5 \%$ the Tdap vaccine; the lowest level of intent was for the influenza vaccine at 58.9\% (Table 2). Of those who had received at least one dose of the HPV vaccine, 32 (66.7\%) received all three doses (Table 2).

Reasons for vaccinating with adolescent recommended vaccines

For parents who had their adolescent vaccinated, a recommendation for receipt by the family physician was either the number one or number two reason for receipt of all four vaccines (Table 3). For influenza vaccine the second and third most commonly reported reasons were that the family had good experience with the vaccine and a desire to protect a family member (Table 3). For Tdap vaccine the number one reason was recommendation by the health department, followed by physician recommendation and to protect a family member that was too young to be vaccinated (Table 3). For MCV4 the second and third reasons for receipt were family/friend recommendation and hearing about the vaccine on the news. For HPV vaccine the second and third most commonly reported reasons were that they had heard about it on the news and a recommendation by the health department (Table 3).

Physician recommendation was also in the top three reasons for parents who intended to have their adolescent vaccinated (Table 3). For intention to receive an influenza vaccine, the three top reasons were (1) family has had good experience with the vaccine, (2) physician recommendation, and (3) to protect a family member (Table 3). For Tdap vaccine the top three reasons were (1) to protect a family member who is too young for vaccination, (2) to protect a family member who has medical problems, and (3) a physician recommendation. For MCV4 vaccine the top three reasons were (1) a physician recommendation, (2) to protect a family member, and (3) hearing about it on the news. For HPV vaccine the top three reasons were (1) hearing about it on the news, (2) a physician recommendation, and (3) a family/friend recommendation.

Reasons for not vaccinating with adolescent recommended vaccines

Among parents whose adolescent had not received and did not intend to have their adolescent receive the influenza vaccine the most commonly reported reasons were: (1) concern it would make my child sick $(69.0 \%)$, (2) concern about side-effects $(62.1 \%)$, and (3) my child didn't need it (58.6\%) (Table 4). 
Table 2. Application of health belief model (HBM) constructs and social norms to inform the parent survey

\begin{tabular}{|c|l|}
\hline Theoretical constructs & \multicolumn{1}{|c|}{ Items per construct (True/False) } \\
\hline \multirow{3}{*}{ Perceived Susceptibility (HBM) } & $\begin{array}{l}\text { - My child is not very likely to get [disease] } \\
\text { - A healthy 40-y-old is more likely to get the flu than my child } \\
\text { - Compared with other children your child's age, your child is more likely to get [flu or meningococcal disease] }\end{array}$ \\
\hline Perceived Severity (HBM) & - Flu/Whooping cough/Meningoccocal disease/HPV illness is [a] serious [illness] \\
\hline Perceived Benefits (HBM) & $\begin{array}{l}\text { - Giving the influenza vaccine to children will decrease their parents' time lost from work } \\
\text { - Giving the influenza vaccine to children decreases their time out of school } \\
\text { - Children should be vaccinated against the flu/whooping cough/meningococcal disease/HPV } \\
\text { - By not getting the Tdap vaccine your child is putting others at risk for disease }\end{array}$ \\
\hline & $\begin{array}{l}\text { - The MCV4 vaccine is very effective at preventing meningococcal disease } \\
\text { - The HPV vaccine is very effective in preventing cervical cancer }\end{array}$ \\
\hline Perceived Barriers (HBM) & $\begin{array}{l}\text { - Pre-teens and teens should only be immunized against serious diseases } \\
\text { - Your child's immune system could be weakened by too many immunizations } \\
\text { - Your child could get sick from the vaccine itself }\end{array}$ \\
\hline Social Norms (TRA) & $\begin{array}{l}\text { - Most parents I know take their children for the flu/Tdap vaccine } \\
\text { - Most people important to me think I would give my child the flu/Tdap/MCV4/HPV vaccine }\end{array}$ \\
\hline
\end{tabular}

For Tdap vaccine, the most common reported reasons for not receiving or not intending to receive vaccines were: (1) concern about adverse effects (66.7\%), (2) didn't know that the vaccine was recommended for adolescents (33.3\%), and (3) my adolescent is scared of needles (33.3\%) (Table 4). Among parents whose adolescent had not received and did not intend to have their adolescent receive the MCV4 vaccine the most commonly reported reasons were: (1) concern about adverse effects $(66.7 \%)$, (2) concern it would make my adolescent sick (58.3\%), and (3) my adolescent is scared of needles $(33.3 \%)$ (Table 4). For HPV vaccine, the most common reported reasons for not receiving and not intending to receive the vaccine were: (1) concern about adverse effects $(65.0 \%)$, (2) concern it would make my adolescent sick (55.0\%), (3) my adolescent didn't need it $(40.0 \%)$, and (4) my adolescent is too young to get it $(40.0 \%)$ (Table 4).

Association between physicians' recommendation for any adolescent vaccine and vaccination

The majority of parents reported that their physician recommended the adolescent vaccines for their child (Table 2). The MCV4 vaccine had the highest report of recommendation (72.7\%) and HPV had the lowest (51.3\%) (Table 2). There was a significant association between physician recommendation for receipt of at least one adolescent vaccine and receipt of Tdap $(\mathrm{p}<0.001)$, MCV4 $(\mathrm{p}<0.001)$, and HPV vaccine $(\mathrm{p}=0.03)$ (Table 5). There was also a significant association between physician recommendation and intent to receive the Tdap vaccine $(\mathrm{p}=0.05), \operatorname{MCV} 4(\mathrm{p}=0.005)$, and HPV vaccine $(\mathrm{p}=0.05)$

Table 3. Reasons for receiving or intending to receive vaccine

\begin{tabular}{|c|c|c|c|c|c|c|c|c|}
\hline & \multicolumn{4}{|c|}{ Reasons for receipt of adolescent vaccines } & \multicolumn{4}{|c|}{ Reasons for intention to receive adolescent vaccines } \\
\hline & $\begin{array}{c}\text { Influenza } \\
(\mathrm{n}=88) \\
\mathrm{N}(\%)\end{array}$ & $\begin{array}{c}\text { Tdap } \\
(\mathrm{n}=98) \\
\mathrm{N}(\%)\end{array}$ & $\begin{array}{c}\text { MCV4 } \\
(n=80) \\
N(\%)\end{array}$ & $\begin{array}{c}\text { HPV } \\
(n=48) \\
N(\%)\end{array}$ & $\begin{array}{c}\text { Influenza } \\
\text { (n=44) } \\
N(\%)\end{array}$ & $\begin{array}{c}\text { Tdap } \\
(n=14) \\
N(\%)\end{array}$ & $\begin{array}{c}\text { MCV4 } \\
(n=25) \\
N(\%)\end{array}$ & $\begin{array}{c}\text { HPV } \\
(n=47) \\
N(\%)\end{array}$ \\
\hline $\begin{array}{l}\text { Our family doctor } \\
\text { recommended it for my child }\end{array}$ & $77(87.5)^{*}$ & $35(35.7)^{\dagger}$ & $73(91.3)^{*}$ & $46(95.8)^{*}$ & $35(79.5)^{\dagger}$ & $4(28.6)^{\ddagger}$ & $13(52.0)^{*}$ & $21(45.7)^{\dagger}$ \\
\hline To protect a family member & $54(61.4)^{\ddagger}$ & - & $22(27.5)$ & - & $29(65.9)^{\ddagger}$ & - & $12(48.0)^{\dagger}$ & - \\
\hline Too young to be vaccinated & - & $32(32.7)^{\ddagger}$ & - & - & - & $9(64.3)^{*}$ & - & - \\
\hline $\begin{array}{l}\text { Cannot be vaccinated } \\
\text { for medical reasons }\end{array}$ & - & $16(16.3)$ & - & - & - & $5(35.7)^{\dagger}$ & - & - \\
\hline $\begin{array}{l}\text { Family has had good } \\
\text { experience with the vaccine }\end{array}$ & $73(83.0)^{\dagger}$ & - & - & - & $39(88.6)^{*}$ & - & - & - \\
\hline I heard about it on the news & $38(43.2)$ & $29(29.6)$ & $35(43.8)^{\ddagger}$ & $21(43.8)^{\dagger}$ & $25(56.8)$ & $4(28.6)^{\ddagger}$ & $12(48.0)^{\dagger}$ & $27(57.5)^{*}$ \\
\hline $\begin{array}{l}\text { It was recommended by } \\
\text { the health department }\end{array}$ & $23(26.1)$ & $88(89.8)^{*}$ & $23(28.8)$ & $16(33.3)^{\ddagger}$ & $11(25.0)$ & $4(28.6)^{\ddagger}$ & $6(24.0)$ & $8(17.0)$ \\
\hline $\begin{array}{l}\text { It was recommended by a } \\
\text { friend/family member }\end{array}$ & $30(34.1)$ & $17(17.4)$ & $61(76.2)^{+}$ & $11(22.9)$ & $18(40.9)$ & $2(14.3)$ & $5(20.0)$ & $10(21.3)^{\ddagger}$ \\
\hline
\end{tabular}

Notes: *Primary reason for vaccine acceptance. ${ }^{\dagger}$ Second most reason for vaccine acceptance. ${ }^{~}$ Third most reason for vaccine acceptance. 
Table 4. Reasons for not receiving or not intending to receive vaccine

\begin{tabular}{|c|c|c|c|c|}
\hline & $\begin{array}{c}\text { Influenza }(\mathrm{n}=30) \\
\mathrm{N}(\%)\end{array}$ & $\begin{array}{c}\text { Tdap } \\
(n=6) \\
N(\%)\end{array}$ & $\begin{array}{c}\text { MCV4 } \\
(n=12) \\
N(\%)\end{array}$ & $\begin{array}{c}\text { HPV } \\
(n=20) \\
N(\%)\end{array}$ \\
\hline Concern about side-effects & $18(62.1)^{\dagger}$ & $4(66.7) *$ & $8(66.7) *$ & $13(65.0) *$ \\
\hline Concern it would make my child sick & $20(69.0)^{*}$ & $1(16.7)$ & $7(58.3)^{+}$ & $11(55.0)^{\dagger}$ \\
\hline $\begin{array}{l}\text { Didn't know that vaccine was } \\
\text { recommended for children }\end{array}$ & $5(17.2)$ & $2(33.3)^{+}$ & $5(41.7)$ & - \\
\hline My child didn't need it & $17(58.6)^{\ddagger}$ & $1(16.7)$ & - & $8(40.0)^{\ddagger}$ \\
\hline May increase sexual activity & - & - & - & $3(15.0)$ \\
\hline My child is too young to get it & - & - & - & $8(40.0)^{\ddagger}$ \\
\hline My child is scared of needles & $10(34.5)$ & $2(33.3)^{\dagger}$ & $4(33.3)^{\ddagger}$ & $6(30.0)$ \\
\hline $\begin{array}{l}\text { Our family doctor did } \\
\text { not recommend it }\end{array}$ & $7(24.1)$ & $0(0)$ & $3(25.0)$ & $7(35.0)$ \\
\hline Didn't know where to go to get it & $0(0)$ & $0(0)$ & - & - \\
\hline Hard to find time to fit it in & $4(13.8)$ & $0(0)$ & $1(8.3)$ & $3(15.0)$ \\
\hline The vaccine costs too much & $3(10.3)$ & $0(0)$ & $0(0)$ & $2(10.0)$ \\
\hline Vaccine does not prevent disease & $9(31.0)$ & - & - & - \\
\hline
\end{tabular}

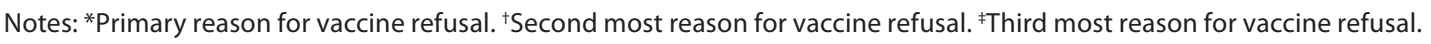

(Table 5). Physician recommendation was not associated with receipt of or intent to receive an influenza vaccine (Table 5).

Differences in attitudes and beliefs and receipt or intent to receive adolescent vaccinations

Parents whose adolescent had received any of the four vaccines showed significantly higher perceived susceptibility to disease $(p<0.001)$, perceived severity of disease $(<0.001)$, perceived benefit of vaccination $(\mathrm{p}<0.001)$, and social norms $(\mathrm{p}<0.001)$ and reported lower perceived barriers to vaccination $(\mathrm{p}<0.001)$ than parents whose adolescent did not receive any of the four vaccines (Table 6).

Parents who intended to have their child vaccinated with any of the four vaccines reported significantly higher perceived disease susceptibility $(p=0.03)$, disease severity $(0.02)$, and higher perceived benefit of vaccination $(\mathrm{p}=0.02)$ (Table 6).

\section{Discussion}

To our knowledge this is the first report of parental attitudes toward adolescent vaccines and influence of a physician

Table 5. Association of physician recommendation for any adolescent vaccine and receipt of or intent to receive recommended vaccine

\begin{tabular}{|c|c|c|c|c|}
\hline & \multicolumn{2}{|c|}{ Receipt of vaccine } & \multicolumn{2}{c|}{ Intent to receive vaccine } \\
\hline & $\mathbf{N}(\%)$ & p-value & $\mathbf{N}(\%)$ & p-value \\
\hline Influenza vaccine & $82(70.1)$ & 0.71 & $43(58.9)$ & 0.95 \\
\hline Tdap vaccine & $96(98.0)$ & $<\mathbf{0 . 0 0 1 *}$ & $10(50.0)$ & $\mathbf{0 . 0 5}^{*}$ \\
\hline MCV4 vaccine & $79(67.5)$ & $<\mathbf{0 . 0 0 1}^{*}$ & $22(59.5)$ & $\mathbf{0 . 0 0 5}^{*}$ \\
\hline HPV vaccine & $47(40.2)$ & $\mathbf{0 . 0 3}^{*}$ & $43(64.2)$ & $\mathbf{0 . 0 5}^{*}$ \\
\hline
\end{tabular}

Note: *Significant at $a \leq 0.05$ recommendation on uptake, as well as intention to receive of all four adolescent recommended vaccines. Also, we were able to compare how attitudes differed between the vaccines. We found higher vaccination uptake than reported for the state of Georgia for Tdap vaccine, with Georgia estimates for Tdap coverage of $68.0 \%$ (US $85.3 \%$ ). ${ }^{2}$ We also found higher influenza vaccination uptake at $82.6 \%$ while a national estimate of influenza vaccination coverage among $13-17$ y olds in $2011-2012$ was $33.7 \% .{ }^{19}$ Some of this higher than national average may be attributable to school-located influenza vaccination clinics conducted in the study county in the same time period as our survey. We found that uptake of MCV4 and HPV vaccine was similar to recent Georgia estimates of $67.7 \%$ for MCV4 (US 70.5\%) and $48.4 \%$ (US $53.0 \%$ ) for at least one dose of HPV vaccine in females. ${ }^{2}$

Further, we found that there was a high frequency of physician recommendation for all four vaccines. In addition, when it came to reasons that a parent had their adolescent vaccinated, physician recommendation was important for all four vaccines. For parents whose adolescent had not been vaccinated but intended to also reported protection for a family member as an important reason. To our knowledge this study is the first to show that physician recommendation for any of the four vaccines was significantly associated with parents having their adolescent vaccinated or intending to have their adolescent vaccinated for Tdap, MCV4, and HPV. Physician recommendation has been study for individual vaccines. Physician recommendation has been shown to be associated with an increase in the odds of series initiation for HPV vaccine among adolescent girls. ${ }^{20,21}$ Physician recommendation was also associated with increased influenza vaccination coverage among minority adults. ${ }^{22}$

Hearing about vaccination in the news was also an important reason for vaccine acceptance. This highlights the important role public health communications by the media may play in public 
Table 6. Differences between parental attitudes and barriers scores

\begin{tabular}{|c|c|c|c|c|c|c|}
\hline Theoretical constructs & $\begin{array}{l}\text { Receipt of } \\
\text { vaccine } \\
\text { Mean (SD) }\end{array}$ & $\begin{array}{l}\text { No receipt of } \\
\text { vaccine } \\
\text { Mean (SD) }\end{array}$ & p-value & $\begin{array}{l}\text { Intend to } \\
\text { vaccinate } \\
\text { Mean (SD) }\end{array}$ & $\begin{array}{l}\text { No intention to } \\
\text { vaccinate } \\
\text { Mean (SD) }\end{array}$ & p-value \\
\hline Perceived Susceptibility (HBM) & $3.0(1.7)$ & $1.0(1.0)$ & $<0.001 *$ & $3.12(1.7)$ & $2.63(1.7)$ & $0.03 *$ \\
\hline Perceived Severity (HBM) & $3.84(0.5)$ & $3.0(1.0)$ & $<0.001 *$ & $3.89(0.3)$ & $3.70(0.7)$ & $0.02 *$ \\
\hline Perceived Benefits (HBM) & $8.33(1.73)$ & $1.5(2.1)$ & $<0.001 *$ & $8.48(1.4)$ & $7.74(2.6)$ & $0.02 *$ \\
\hline Perceived Barriers (HBM) & $1.17(1.0)$ & $2.0(1.0)$ & $<0.001 *$ & $1.14(1.0)$ & $1.28(1.1)$ & 0.31 \\
\hline Social Norms (TRA) & $4.48(1.9)$ & $2.67(2.1)$ & $<0.001 *$ & $4.44(1.8)$ & $4.42(2.0)$ & 0.94 \\
\hline
\end{tabular}

Note: *Significant at $a \leq 0.05$

perceptions of vaccines and diseases, and suggests that media and social marketing campaigns should be engaged as informed advocates of vaccination. The primary reasons for parents not having vaccinated or not intending to vaccinate their adolescent were safety concerns, including concerns about adverse effects and concern the vaccine would make their child sick. Our findings are similar to other studies that found that concerns about vaccine safety and adverse events were inversely associated with HPV and influenza vaccine acceptance. ${ }^{13,16,23}$ Parents need to be made aware of how much care and attention is paid to ensuring that vaccines are as safe as possible. Knowing this may increase confidence in the vaccine system and help shape beliefs. Given the breadth, depth, and rigor of the US vaccine safety system including the ability to rapidly detect potential vaccine adverse events, education strategies to increase parental knowledge in this area might change beliefs and improve confidence and trust in the system. Similar to other studies, feeling that their adolescent did not need the vaccine (influenza and HPV) was also reported as a reason for non-acceptance. ${ }^{13,23}$ Views that HPV vaccine would lead to sexual activity have been reported,,$^{13}$ and we found that a parent feeling that their adolescent was too young to get the HPV vaccine was an important reason for non-vaccination. Importantly though, a recent study by Bednarczyk et al. found that there was no increase in sexual activity-related outcomes following HPV vaccination among youth. ${ }^{24}$ We found that there was very little concern about increase in sexual activity among parents in our study.

Factors associated with intention to receive any of the four recommended adolescent vaccines were perceived susceptibility to and severity of disease and perceived benefit of vaccination. Perceived benefits included vaccine effectiveness, not getting vaccinated putting others at risk, and vaccination decreasing parents' time off work and adolescent's time out of school. Developing and implementing strategies to increase perceived benefits of vaccination for adolescents may serve to increase vaccine uptake. Social norms measure the participants' belief that their medical providers, family, and others would approve of them getting their adolescent vaccinated. While social norms have been found in other studies to be associated with receiving a vaccine and intention to vaccinate $e^{15,25-28}$ our study found this relationship in only those who had received vaccination. On the other hand, we identified the importance of a family member or friend recommendation and physician recommendation among parents whose adolescent had received one of the four vaccines in our study population, suggesting that campaigns for adolescent vaccination may be most successful if they include information about endorsement of vaccination by physicians and trusted individuals and focus on vaccination as a social norm. This finding also underscores the importance of developing interventions to be implemented on various levels and targeting multiple people, including parents, providers, school administrators, peers, and teachers.

There are several strengths to our study. First, our study site consists of a high minority, low SES population that has traditionally been a hard-to-reach population. Second, our study focuses on all four adolescent vaccines and how recommendation of any one impacts the uptake of all four. Finally, our study is unique in that it assesses the impact and differences in parental attitudes on both receipt and intention to receive adolescent vaccines.

\section{Limitations}

The findings in this report are subject to several limitations. The study population is from one county in Georgia and the majority of participants were on Medicaid, so the results may not be generalizable to populations residing in other geographical locations. Further, the rate of return of consent forms was low, reducing the power of our analysis and the precision of our effect estimates. However, low response rates are a constant challenge for school-based studies, and our response rate is comparable to that of other studies that mailed surveys. ${ }^{29-32}$ Additionally, we had a very short timeline in which to complete the baseline surveys (five weeks) before the intervention began. Parents who participated in the telephone survey may differ in important ways from the majority of parents who opted not to take the survey. The strength of physician recommendation was not assessed, and future studies should follow-up on how the strength of the recommendation impacts intention and receipt. Additionally, our outcomes of vaccination were based on self-report and not actual medical record review; it is possible that parents may have inaccurately reported their child's vaccination history. Finally, there may be social desirability bias since the survey was conducted over the phone.

\section{Conclusions}

These findings suggest that a physician recommendation is critical for enhancing adolescent vaccination uptake and may serve to help ensure that those who intend to have their adolescent vaccinated actually do so, especially for Tdap, MCV4, and HPV. Further, providers should be informed that their active 
recommendation for adolescent vaccination and explanation about the vaccines' effectiveness and safety is critical to parental acceptance. Understanding the correlates of vaccine uptake separate from intention to vaccinate is key to designing interventions that target both intentions to receive and ultimately receipt of vaccine. Future studies should investigate whether interventions targeting perceived susceptibility, severity, and benefits to adolescent vaccination increase vaccine uptake.

\section{Materials and Methods}

\section{Study population}

The study population consisted of a sample of parents of students enrolled in a middle- or high-school participating in a trial of a vaccination promotion intervention in one county in Georgia. Eleven schools participated. In 2010, the county population was 54.2\% African American and 92.2\% urban; 23.4\% of children $12-17$ y old were living in poverty. ${ }^{33}$ Eligibility criteria for the survey included (1) residing in the target county, (2) having adolescent(s) enrolled in a participating middle- or high-school, and (3) providing written consent to participate. Study protocols were reviewed and approved by the Emory Institutional Review Board (IRB) as well as the IRBs of collaborating institutions.

\section{Data collection}

Data for the present study were derived from telephone surveys administered to parents of students in our participating schools at baseline, prior to intervention implementation (NovemberDecember 2011). A random sample of parents was taken from participating schools. In October 2011, packets were mailed or sent home from the schools to a sample of parents (or primary caretaker) of children enrolled in either participating middleor high-schools in the study county. The packets included an invitation letter briefly describing the phone survey, a consent form, a contact information sheet, and an envelope to return the completed materials to the school. Interested parents were instructed to sign the consent form and complete the contact information sheet (which asked for phone number and best times to call to complete the survey) and send both back to school with their child. A reminder call was made to parents two weeks after the initial packets were mailed. All surveys were completed by Thanksgiving in order to be completed before the intervention was implemented in December 2011. A \$20 Walmart gift card was offered as an incentive to parents. Telephone surveys were conducted by trained research assistants and were approximately $25 \mathrm{~min}$ in duration. At baseline, 2552 survey invitation packets were mailed to parents/guardians of enrolled middle- and highschool students soliciting their participation in a telephone survey. Of these, 198 signed consent forms were returned (return rate $=7.8 \%$ ). Of the returned signed consent forms, 114 telephone surveys were conducted (response rate $=57.6 \%$ ).

\section{Survey instrument}

The telephone survey was designed to investigate demographic, behavioral and psychosocial factors associated with parental acceptance of vaccination for their adolescent children. The Health Belief Model (HBM) was used to guide survey development, allowing assessment of the effects of psychosocial factors associated with vaccine acceptance among parents. ${ }^{34} \mathrm{HBM}$-guided questions were adapted from surveys with demonstrated reliability and validity among parents. ${ }^{35}$ The survey was designed to assess four major HBM components: (1) perceived susceptibility to disease; (2) perceived severity of disease; (3) perceived benefits of vaccination; and (4) perceived barriers to vaccination. The Theory of Reasoned Action (TRA) was also used to guide the parent survey development in order to assess the importance of social norms. ${ }^{36}$

\section{Measures}

\section{Main outcome measures}

The main outcomes of interest were parent-reported receipt, intention to have their adolescent vaccinated with the four recommended adolescent vaccines, and whether or not there had been a physician recommendation for vaccination. A separate question was asked for each vaccine. All were dichotomous variables (Yes/No). Receipt of vaccine was measured by asking "Has your child received the flu/Tdap/MCV4/HPV vaccine?" Intention to receive a vaccination was measured by asking: "Do you plan to have your child receive the Tdap/MCV4/HPV/flu vaccine?" Physician recommendation was measured by asking: "Did a doctor recommend that your child receive a flu/Tdap/ MCV4/HPV vaccine?"

\section{Demographic information}

Participants reported child's gender (dichotomous), race (categorical), age (continuous), and insurance coverage (categorical).

Attitudes and beliefs toward influenza and influenza vaccination

Questions specific to: (1) perceived severity of infection for adolescents (1 item per vaccine), (2) perceived susceptibility of adolescent to infection (3 items for influenza and Tdap, 2 items for MCV4, and 1 for HPV), (3) perceived barriers to vaccination for adolescents (3 items per vaccine), (4) perceived benefits of vaccination for adolescents (4 items for influenza and 2 for Tdap, MCV4, and HPV), and (5) perceived social norms about getting adolescents vaccinated (2 items for influenza, Tdap, and HPV and 1 item for MCV4) were asked of parents. Responses were either true (1) or false (0). A true/false option was used rather than a Likert-rating in an attempt to reduce possible confusion resulting from offering a more complex response range. Items were summed per construct, resulting in five separate attitude and belief scores.

\section{Data analysis}

First, questions assessing psychosocial constructs were combined into five separate scales scores. Table 2 shows how key constructs from the HBM and social norms from TRA map onto questions on the parent survey used to create scales. Descriptive statistics assessed the distribution of demographic, behavioral, and psychosocial variables relating to adolescent vaccination. Because of small sample size, Fisher's exact test was performed to assess the association between physician recommendation for any of the four vaccines and receipt or intent to receive each of the vaccines. Chi-square tests were used to assess differences in psychosocial constructs among parents who received and did not receive the vaccines and among those who intended and did not intend to have their adolescent vaccinated. All analyses were conducted using SAS9.2. Given the nature of the data collection (via telephone survey), there were no missing data for all variables in the study. 


\section{Potential Conflicts of Interest}

No potential conflicts of interest were disclosed.

\section{Acknowledgments}

We would like to thank Dr Ketty M Gonzalez, District Health Director for the East Central Health District, the school district administrators, and principals, teachers and staff of participating schools. This project is funded by the Centers for Disease Control and Prevention cooperative agreement 5UO1IP000413. Dr Painter was also supported by grant Award Number T32AI074492 from the National Institute of Allergy and Infectious Disease, National Institutes of Health (NIH). Dr Sales was supported by grant K01 MH085506 from the National Institute of Mental Health, NIH.

\section{References}

1. Centers for Disease Control and Prevention. Immunization Schedules. June 2012.

2. Centers for Disease Control and Prevention (CDC). National and state vaccination coverage among adolescents aged 13-17 years--United States, 2011. MMWR Morb Mortal Wkly Rep 2012; 61:671-7; PMID:22932301

3. Davis MM, Zimmerman JL, Wheeler JR, Freed GL. Childhood vaccine purchase costs in the public sector: past trends, future expectations. Am J Public Health 2002; 92:1982-7; PMID:12453820; http:// dx.doi.org/10.2105/AJPH.92.12.1982

4. Lindley MC, Shen AK, Orenstein WA, Rodewald LE, Birkhead GS. Financing the delivery of vaccines to children and adolescents: challenges to the current system. Pediatrics 2009; 124(Suppl 5):S548-57; PMID:19948587; http://dx.doi.org/10.1542/ peds.2009-1542O

5. Kimmel SR. Adolescent Vaccination: Physician Challenges and Solutions. J Adolesc Health 2010; 46:S16-23; http://dx.doi.org/10.1016/j. jadohealth.2009.11.219

6. National Vaccine Advisory Committee. The promise and challenge of adolescent immunization. Am J Prev Med 2008; 35:152-7; PMID:18617084; http:// dx.doi.org/10.1016/j.amepre.2008.03.034

7. Rand CM, Shone LP, Albertin C, Auinger P, Klein JD, Szilagyi PG. National health care visit patterns of adolescents: implications for delivery of new adolescent vaccines. Arch Pediatr Adolesc Med 2007; 161:252-9; PMID:17339506; http://dx.doi. org/10.1001/archpedi.161.3.252

8. Brewer NT, Fazekas KI. Predictors of HPV vaccine acceptability: a theory-informed, systematic review. Prev Med 2007; 45:107-14; PMID:17628649; http:// dx.doi.org/10.1016/j.ypmed.2007.05.013

9. Dempsey AF, Davis MM. Overcoming barriers to adherence to HPV vaccination recommendations. Am J Manag Care 2006; 12(Suppl):S484-91; PMID:17203992

10. Szilagyi PG, Rand CM, McLaurin J, Tan L, Britto M, Francis A, et al.; Working Group on Adolescent Vaccination in the Medical Home. Delivering adolescent vaccinations in the medical home: a new era? Pediatrics 2008; 121(Suppl 1):S15-24; PMID:18174317; $\quad$ http://dx.doi.org/10.1542/ peds.2007-1115C

11. Lindley MC, Boyer-Chu L, Fishbein DB, Kolasa M, Middleman AB, Wilson T, et al.; Working Group on the Role of Schools in Delivery of Adolescent Vaccinations. The role of schools in strengthening delivery of new adolescent vaccinations. Pediatrics 2008; 121(Suppl 1):S46-54; PMID:18174320; http://dx.doi.org/10.1542/peds.2007-1115F

12. Schaffer SJ, Fontanesi J, Rickert D, Grabenstein JD, Rothholz MC, Wang SA, et al.; Working Group on Complementary Settings. How effectively can health care settings beyond the traditional medical home provide vaccines to adolescents? Pediatrics 2008; 121(Suppl 1):S35-45; PMID:18174319; http:// dx.doi.org/10.1542/peds.2007-1115E
13. Woodhall SC, Lehtinen M, Verho T, Huhtala H, Hokkanen M, Kosunen E. Anticipated acceptance of HPV vaccination at the baseline of implementation: a survey of parental and adolescent knowledge and attitudes in Finland. J Adolesc Health 2007; $40: 466$ 9; PMID:17448408; http://dx.doi.org/10.1016/j. jadohealth.2007.01.005

14. Allison MA, Reyes M, Young P, Calame L, Sheng X, Weng HY, et al. Parental attitudes about influenza immunization and school-based immunization for school-aged children. Pediatr Infect Dis J 2010; 29:751-5; PMID:20308935; http://dx.doi. org/10.1097/INF.0b013e3181d8562c

15. Daley MF, Crane LA, Chandramouli V, Beaty $\mathrm{BL}$, Barrow J, Allred N, et al. Misperceptions about influenza vaccination among parents of healthy young children. Clin Pediatr (Phila) 2007; 46:408-17; PMID:17556737; http://dx.doi. org/10.1177/0009922806298647

16. Carpenter LR, Lott J, Lawson BM, Hall S, Craig AS, Schaffner W, et al. Mass distribution of free, intranasally administered influenza vaccine in a public school system. Pediatrics 2007; 120:e1728; PMID:17591766; http://dx.doi.org/10.1542/ peds.2006-2603

17. Timmermans DR, Henneman L, Hirasing RA, van der Wal G. Attitudes and risk perception of parents of different ethnic backgrounds regarding meningococcal C vaccination. Vaccine 2005; 23:3329-35; PMID:15837239; http://dx.doi. org/10.1016/j.vaccine.2005.01.075

18. Dorell C, Yankey D, Strasser S. Parent-reported reasons for nonreceipt of recommended adolescent vaccinations, national immunization survey: teen, 2009. Clin Pediatr (Phila) 2011; 50:1116-24; PMID:21856964; http://dx.doi. org/10.1177/0009922811415104

19. Centers for Disease Control and Prevention. Flu Vaccination Coverage, United States, 2011-12 Influenza Season 2012.

20. Brewer NT, Gottlieb SL, Reiter PL, McRee AL, Liddon N, Markowitz L, et al. Longitudinal predictors of human papillomavirus vaccine initiation among adolescent girls in a high-risk geographic area. Sex Transm Dis 2011; 38:197-204; PMID:20838362; http://dx.doi.org/10.1097/OLQ.0b013e3181f12dbf

21. Guerry SL, De Rosa CJ, Markowitz LE, Walker S, Liddon N, Kerndt PR, et al. Human papillomavirus vaccine initiation among adolescent girls in highrisk communities. Vaccine 2011; 29:2235-41; PMID:21288799; http://dx.doi.org/10.1016/j. vaccine.2011.01.052

22. Winston CA, Wortley PM, Lees KA. Factors associated with vaccination of medicare beneficiaries in five U.S. communities: Results from the racial and ethnic adult disparities in immunization initiative survey, 2003. J Am Geriatr Soc 2006; 54:303-10; PMID:16460383 http://dx.doi.org/10.1111/j.1532-5415.2005.00585.x

23. Gargano LM, Painter JE, Sales JM, Morfaw C, Jones LM, Murray D, et al. Seasonal and 2009 H1N1 influenza vaccine uptake, predictors of vaccination, and self-reported barriers to vaccination among secondary school teachers and staff. Hum Vaccin 2011; 7:89-95; PMID:21263225; http://dx.doi. org/10.4161/hv.7.1.13460
24. Bednarczyk RA, Davis R, Ault K, Orenstein W, Omer SB. Sexual activity-related outcomes after human papillomavirus vaccination of 11- to 12-year-olds. Pediatrics 2012; 130:798-805; PMID:23071201; http://dx.doi.org/10.1542/peds.2012-1516

25. Conroy K, Rosenthal SL, Zimet GD, Jin Y, Bernstein DI, Glynn S, et al. Human papillomavirus vaccine uptake, predictors of vaccination, and self-reported barriers to vaccination. J Womens Health (Larchmt) 2009; 18:1679-86; PMID:19785564; http://dx.doi. org/10.1089/jwh.2008.1329

26. Daley MF, Crane LA, Chandramouli V, Beaty BL, Barrow J, Allred N, et al. Influenza among healthy young children: changes in parental attitudes and predictors of immunization during the 2003 to 2004 influenza season. Pediatrics 2006; 117:e26877; PMID:16452334; http://dx.doi.org/10.1542/ peds.2005-1752

27. Mok E, Yeung SH, Chan MF. Prevalence of influenza vaccination and correlates of intention to be vaccinated among Hong Kong Chinese. Public Health Nurs 2006; 23:506-15; PMID:17096775; http://dx.doi.org/10.1111/j.1525-1446.2006.00590.x

28. Sturm LA, Mays RM, Zimet GD. Parental beliefs and decision making about child and adolescent immunization: from polio to sexually transmitted infections. J Dev Behav Pediatr 2005; 26:441-52; PMID:16344662; http://dx.doi. org/10.1097/00004703-200512000-00009

29. Shih TFX. Comparing response rates from web and mail surveys: A meta-analysis. Field Methods 2008; 20:249-71; http://dx.doi. org/10.1177/1525822X08317085

30. Claudio L, Stingone JA. Improving sampling and response rates in children's health research through participatory methods. J Sch Health 2008; 78:445-51; PMID:18651932; http://dx.doi. org/10.1111/j.1746-1561.2008.00328.x

31. Ji PY, Pokorny SB, Jason LA. Factors influencing middle and high schools' active parental consent return rates. Eval Rev 2004; 28:578-91; PMID:15486162; http://dx.doi.org/10.1177/0193841X04263917

32. McMorris BJ, Clements J, Evans-Whipp T, Gangnes $\mathrm{D}$, Bond L, Toumbourou JW, et al. A comparison of methods to obtain active parental consent for an international student survey. Eval Rev 2004; 28:64-83; PMID:14750292; http://dx.doi. org/10.1177/0193841X03257532

33. East Central Health District. County Health Departments - Richmond County. 2013.

34. Champion V, Skinner C. The Health Belief Model In: Glanz K RB, Viswanath K, ed. Health behavio and health education: Theory, research, and practice. San Francisco, CA: Jossey-Bass, 2008:45-65.

35. Sales JM, Painter JE, Pazol K, Gargano LM, Orenstein W, Hughes JM, et al. Rural parents' vaccinationrelated attitudes and intention to vaccinate middle and high school children against influenza following educational influenza vaccination intervention. Hum Vaccin 2011; 7:1146-52; PMID:22048112; http:// dx.doi.org/10.4161/hv.7.11.17891

36. Fishbein M, Ajzen I. Belief, attitude, intention, and behavior: An introduction to theory and research. Reading, MA: Addison-Wesley, 1975. 